\title{
Tips for using students during times of change in health care: lessons from the literature and from practice
}

This article was published in the following Dove Press journal:

Advances in Medical Education and Practice

27 July 2017

Number of times this article has been viewed

\author{
Saravana Kumar' \\ Ingrid L Lensink ${ }^{2}$ \\ Catherine Turnbull ${ }^{2}$ \\ 'School of Health Sciences, Sansom \\ Institute for Health Research, \\ University of South Australia, \\ Adelaide, SA, Australia; ${ }^{2}$ Office for \\ Professional Leadership, SA Health, \\ Adelaide, SA, Australia
}

Correspondence: Saravana Kumar School of Health Sciences, Sansom Institute for Health Research, GPO Box 247I, University of South Australia, Adelaide, SA 5000, Australia

Tel +6I 883022085

Fax +61883022766

Email saravana.kumar@unisa.edu.au
Background: It is often said that the only constant in health care is change. While change is inevitable, implementing change in health care is complex, and health care stakeholders are often confronted by numerous barriers and challenges. Historically, students have been an integral part of the health system through aspects such as clinical placements, and hence, may play a role during times of change.

Aim: The aim of this study is to provide strategies for using students as positive agents of change by discussing opportunities and highlighting challenges.

Method: The tips proposed in this commentary are derived from the literature, identified using a systematic search, and from our experiences at the "coal face" of engaging students during times of change.

Results: This article highlights specific challenges, targeted opportunities, and critical success factors of using students as agents of change. Students can play an important role in enhancing service provision, providing opportunities for staff recognition, and being enablers to drive, implement, and evaluate change in the health system and wider community. However, in order to achieve these positive impacts, it is imperative to recognize and address staff concerns early and build upon a number of critical success factors. These critical success factors such as intersectoral engagement, clarity, collaboration, support, training, resources, and ongoing evaluation can "make or break" students' involvement in a health service, and therefore, careful and regular consideration of these factors is recommended.

Conclusion: We believe that these tips, synthesized from evidence from the literature and our first-hand experiences, will assist health care stakeholders in utilizing students as timely, effective, and practical agents of change.

Keywords: students, change agents, health service delivery, partnership, leadership, transformation

\section{Introduction}

Health care in the 21 st century is confronted by numerous challenges. The challenges include an aging population that will require significant health care resources, the rise of chronic conditions that impact on the mortality and morbidity of the population, limited health care resources due to efficiency measures necessitated by budgetary constraints, chronic shortage of health care professionals, especially in rural and regional areas, and an increasing focus on consumer-centred care, where the consumer is an active participant in health care decision-making and not merely a passive recipient. ${ }^{1,2}$

As the demand on our health care systems rises, the need to train more health professionals increases. ${ }^{3}$ An important component of health professional training is clinical placements. Clinical placements form a large proportion of the curriculum 
and thus are integral in order for health professionals to gain the clinical skills required to become a competent health professional and obtain qualifications. ${ }^{3}$ Historically, students' engagement with the health services in the form of clinical placements and clinical education exposed students to the foundational knowledge and skills required for their role as future health care practitioners. ${ }^{4}$ As students are very much part of the health system and are generally considered nonthreatening within the workplace, they are ideally placed to assist during times of change. Using students during times of change may have wide-ranging positive impacts. For example, from a student point of view, in New Zealand, nursing students learned to engage with their profession in order to influence change by being part of committees and boards and constructively contributing to change processes and influencing government policy and legislation. ${ }^{5}$ From a health service point of view, engaging with students can result in renewal of the workforce, access to current and contemporary knowledge in health care, innovative thinking and challenging the status quo, resulting in more efficient processes of care and development of a future asset. However, despite these positive outcomes, barriers also persist. For example, a common barrier reported in the literature, in some jurisdictions, is the financial commitment involved in hosting clinical placements. ${ }^{3}$ Therefore, given the important role students play in health service delivery, this commentary aims to provide strategies for using students as agents of change by discussing opportunities and highlighting challenges. The tips provided in this article should assist health care stakeholders in utilizing students as timely, effective, and practical agents of change.

\section{Literature selection process}

As a means of ensuring rigor and transparency in the literature selection process, which was subsequently used to inform the article, a systematic literature search in Medline, CINAHL, EMBASE, and AMED databases was performed in October 2015 through to June 2016. A list of key search terms were grouped into two concepts and used during the literature searching process. Concept One: Clinical placement, challenges, and opportunities. Key words searched as part of this concept included: Student* or Undergraduate or Entry level student* and Clinical placement* or Internship* or Work placement and Benefits or Challenges or Advantages or Barriers or Disadvantages. Concept Two: Impact of students during time of change. Key words searched included: Student* or Undergraduate or Entry level student* and Clinical placement* and Activity based funding OR Service provision or Productivity or Satisfaction or Health outcome or Cost OR
Benefit* or Recruitment or Reputation or Professional development or Accessibility or Capacity or Patient experience or Workforce or Retention or Culture or Skills or Innovation and Organizations or Health provider* or Hospital*. These two concepts were later combined (using AND) to allow for the most number of relevant articles to be captured. In addition, reference lists of papers were scrutinized for additional studies that may have not have been indexed in any of the electronic databases (pearling). The limits were set for humans and English language but no limits were placed on date or type of publication. In order to avoid publication bias, gray literature searching was undertaken through an internet search engine (Google), which sought to identify technical and government reports, doctoral theses, and position papers from professional organizations. Full texts of potentially eligible articles were assessed by two independent reviewers based on inclusion (any publication which had a particular focus on students and their engagement with health system and its outcomes; any publication that reported on barriers and enablers for students and their engagement with health system) and exclusion (any publication that solely had a student training or education [pedagogy] focus; any publication that solely had a focus on educators, supervisors, and tutors; any publication in the form of conference presentations/letters to Editors/newsletters) criteria.

The electronic search yielded a total of 25 citations from the databases searched. No additional citations were identified through other sources. Of the 25 citations, 5 were irrelevant and hence excluded. A total of 20 publications were deemed relevant and considered for inclusion in this review. The reference lists in the 20 included publications were examined for additional literature. No additional publications were identified. All of the 20 included publications were published between 1993 and 2015. A range of research designs were identified, including a systematic review, two cohort studies, and two mixed methods research. Interestingly, the majority of publications reported on research conducted in Australia, highlighting the prominent role of students within Australia's local health settings.

\section{Results and discussion Tip I: use students to enhance direct service provision}

There is consistent literature evidence to indicate that students can play an important and positive role in impacting direct service provision. ${ }^{3,6-10}$ These include increased access to, and time available for, patient care ${ }^{3}$ improved process of care (such as streamlining discharge process) $;^{7,10}$ and opportunities for supervisors to focus on service provision 
(by allocating project-based tasks to students). ${ }^{6}$ Commonly, it is perceived that engaging with students increases staff workload and impacts negatively on their productivity. However, findings from the literature suggest the opposite to be true as Ozelie et $\mathrm{al}^{9}$ revealed that there was no significant difference in clinician productivity with or without a student. Similarly, Thomas et $\mathrm{al}^{11}$ also identified that supervisor's workload decreased as a result of additional work carried out by students. The key tip when using students to enhance service provision is to engage with supervisors early and highlight the important contributions students could add to their workload.

\section{Tip 2: use students to enhance indirect service provision}

In addition to contributing to direct service provision, students can play an important role in other areas of service provision, such as operationalizing quality-improvement activities, providing a student perspective on organizational procedures, and spearheading resource development. As supervisors and staff have to balance clinical priorities with indirect but equally relevant tasks, students provide an ideal avenue to assist in completing these. Students reportedly felt empowered by their applications of knowledge in relation to cost-containment and quality-improvement initiatives. ${ }^{12}$ Research indicates that students value promoting not only diversity in the workplace, but also actively supporting and contributing to their future professions. ${ }^{11}$

\section{Tip 3: consider today's students as tomorrow's workforce}

One of the most exciting aspects of engaging with students is the ability to showcase a health service's strengths and the varied opportunities the health service may offer to its workforce. Given the importance of recruiting a competent and skilled workforce, today's students are tomorrow's workforce. Research indicates that a student's prior knowledge of, and experience in, health services resulted in recruitment and retention efficiencies and development of a "work-ready" workforce. ${ }^{11}$ In addition to the creation of a work-ready and skilled force, the literature points to other organizational benefits. For example, Bowles et $\mathrm{al}^{3}$ revealed that advertising and agency costs were reduced as a result of post-placement recruitment, implying a cost benefit aspect to having students in clinical placements. Similarly, Thomas et $\mathrm{al}^{11}$ also reported that using students who were part of clinical placements within the health service resulted in decreased time and cost required to train graduate recruits.

\section{Tip 4: consider the relationship between students and health service as a "two-way street"}

While engaging with students as part of clinical placements or clinical education may be perceived as merely benefitting students, in reality, the benefits can flow both ways through facilitating collaboration between major stakeholders such

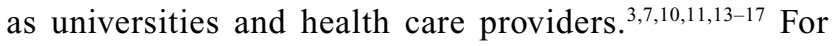
example, health services hosting clinical placements are able to influence curriculum development in order to meet the future needs of both the health care system and professional group. Connolly et $\mathrm{al}^{7}$ specifically highlighted the relationships fostered between hospital and university, and the resulting promotion of the positive impact of the breaking down of "educational silos" as key in achieving joint educational outcomes. Clinical supervisors and staff too benefit through access to ongoing professional development, ready access to cutting-edge resources, and exposure to intersectoral collaboration. In addition to these tangible benefits to clinical supervisors and staff, Thomas et $\mathrm{al}^{11}$ reported that supervisors experienced a real sense of contributing to the future of their profession by supervising students. They also reported that engaging with students resulted in the development of clinical knowledge and reasoning skills as well as prompting them to keep up with the latest evidencebased practice. These positive outcomes have wide ranging impacts on the clinical supervisor, the profession, and health service as a whole.

\section{Tip 5: use students to highlight opportunities for recognition}

Engaging with students can provide ideal opportunities for health services to gain access to tangible (such as financial support) ${ }^{16}$ and intangible (such as academic titles for supervisors) products and outcomes. ${ }^{3,8,15}$ For example, Rodger et $\mathrm{al}^{15}$ investigated a number of allied health professions and the findings revealed that financial rewards and formal recognition and training were positive impacts for uptake and participation in accepting clinical placements. Therefore, using students may provide avenues for supervisors and staff to achieve tangible and intangible recognition.

\section{Tip 6: recognize staff and supervisor's concerns early and put in place enabling strategies}

Despite supervisors and staff recognizing the value of students, the literature also provides evidence of their concerns 
and apprehension. These include increased workload and time commitment, ${ }^{6}$ additional training requirements, ${ }^{18}$ lack of incentives, ${ }^{16}$ demands from student subgroups (e.g., challenging students), and communication difficulties (student and university). ${ }^{8}$ For example, Mather et al ${ }^{14}$ highlighted a number of uncertainties reported by supervisors of nursing students. These include uncertainty in identifying impediments to student learning and providing adequate strategies for growth and change and uncertainty in understanding the expectations of educational programs and curricular, with further clarification required between supervisors and universities. While some of these concerns may be allayed by previous tips, it is important to identify these issues early and intimate enabling strategies. These enabling strategies might include setting clear and realistic expectations of the clinical placement, providing opportunities for regular and timely communication between supervisors at the health service and educators at university, providing training opportunities for upskilling and professional development and managing student expectations.

\section{Tip 7: recognize the evolving context of health services and the complexities that underpin student engagement}

Health services are inherently complex and student engagement, through clinical placements and clinical education, is merely one of the many myriad of services provided by health care organizations. Furthermore, given the complex environment in which these health services operate, the context within which they operate can rapidly evolve. Therefore, when using students, it is vitally important to consider the evolving context of health services and the complexities that underpin student engagement for a number of reasons. First, the priority of the health service might be on patient care, as a means of addressing clinical priorities, and not on student engagement. Second, the heath service may not readily see the value of, or impact from, student engagement in a rapidly evolving context and hence may not prioritize it. Finally, the heath service may perceive or have experienced historical barriers, such as a negative experience, when engaging with students and hence be reluctant to re-engage.

There is evidence from the literature that highlights these issues including inadequate resources, ${ }^{13}$ lack of "placementready" competent students, ${ }^{18}$ diversity in timetabling and placement parameters between universities, ${ }^{10,15}$ availability of staff, infrastructure, workload pressures, the need for a critical mass of experienced supervisors, ${ }^{15}$ and loss of productivity. ${ }^{3}$ Thomas et al $^{11}$ undertook a descriptive survey involving past, present, and future supervisors $(n=132)$ and identified numerous challenges in providing clinical placements such as staffing issues - e.g., high turnover of staff, limited desk space and equipment, variable caseloads, and concerns over student safety and security. These important challenges need to be recognized and, where possible, strategies need to be implemented to address these.

\section{Tip 8: use students to drive, implement, and evaluate change in the health system and the wider community}

Students can play an important role as agents of change by influencing knowledge, attitudes, and practices within the community (patient); advocating on behalf of patients; re-energizing a static health system with new knowledge, theory, and desire for improved patient care; and providing a cost-effective means of trialing new processes of care. For example, Aroian ${ }^{12}$ and Sahai and Kotwal ${ }^{19}$ reported that students recognized themselves as change agents, feeling empowered and believing they can make a difference. Students in this study were able to provide health education that effected changes in knowledge, attitudes, and practices within a community. ${ }^{19}$ Anderson ${ }^{20}$ extends this further by highlighting that students can advocate for change in practice and health policy by actively involving their professional organization, participating in committees/boards, and constructively contributing to change processes involving themselves in their educational institution and influencing government policy and legislation.

Aroian ${ }^{12}$ comments that students' newly acquired theory, knowledge, and desire for quality patient care permeate the professional work environment and allow changes to happen. Klinger and Bossers ${ }^{21}$ describe the benefits that flow to community agency partners and occupational therapy students from an innovative, integrated fieldwork model that links students with service agencies. The findings from this initiative highlight a cost-effective way to demonstrate the value of occupational therapy and to deliver multiple community development projects.

\section{Tip 9: using students during times of change is underpinned by a number of critical success factors}

While students could play an important role during times of change and add wonderful diversity and provide opportunities to drive change, it is important to recognize that there are a number of critical success factors that can "make or break" their involvement. These include inter-sectoral/stakeholders 
engagement; collaboration and support; ${ }^{3,6,14,20,22}$ adequate resources, recognition, support, and training; ${ }^{11,14,15,17,18,21}$ regular evaluation; ${ }^{8,10,16,23}$ and clarity on placement parameters. ${ }^{8,9,14}$ It is important that these critical success factors are identified early and implemented systematically prior to using students within the health service. Given that no two health services are exactly the same, these critical success factors will be dependent on the health service and are likely to change. Therefore, careful and regular consideration of these factors is recommended.

\section{Conclusion}

Students can be important and valuable assets during times of change as they have historically been an integral part of the health system. They play an important role in direct and indirect service provision and can generate positive impacts at patient, discipline, organization, and community levels and can act directly as change agents. However, it should be recognized that for students to succeed in these complex and evolving contexts, a number of critical success factors need to be considered. These factors act as ameliorators of barriers and can assist in successful integration of students during times of change. By following these tips, we believe health care stakeholders can utilize students as timely, effective, and practical agents of change.

\section{Acknowledgments}

The authors would like to thank Rebecca Mumme and Esther Tian for their assistance in formatting this article.

\section{Disclosure}

The authors report no conflicts of interest in this work. The authors alone are responsible for the content and writing of the manuscript.

\section{References}

1. Armstrong BK, Gillespie JA, Leeder SR, Rubin GL, Russell LM. Challenges in health and health care for Australia. Med J Aust. 2007;187(9):485-489.

2. Kumar S, Osborne K, Lehmann T. Clinical supervision of allied health professionals in country South Australia: a mixed methods study. Aust J Rural Health. 2015;23(5):265-271.

3. Bowles KA, Haines T, Molloy E, et al. The costs and benefits of providing undergraduate student clinical placements for a health service organisation: a rapid review. Available from: http://www.heti.nsw.gov.au/Global/ ICTN/Hunter\%20and\%20Coast $\% 20$ ICTN/The $\% 20$ Cost $\% 20$ and $\% 20$ Benefits\%20of\%20CP\%20for\%20HSP.pdf. Accessed May 8, 2017.
4. Thew M, Hargreaves A, Cronin-Davis J. An evaluation of a role-emerging practice placement model for a full cohort of occupational therapy students. Br J Occup Ther. 2008;71(8):348-353.

5. Godwin H, Heymann SJ. A call to action: training public health students to be effective agents for social change. Am J Public Health. 2015;105(S1): S34-S37.

6. Ash S, Martin EK, Rodger S, Clark M, Graves N. Student and supervisor productivity change during nutrition and dietetic practice placements: a cohort study. Nutr Diet. 2015;72(2):163-169.

7. Connolly M, Sweet L, Campbell D. What is the impact of longitudinal rural medical student clerkships on clinical supervisors and hospitals? Aust J Rural Health. 2014;22(4):179-188.

8. Courtney-Pratt H, Ford K, Marlow A. Evaluating, understanding and improving the quality of clinical placements for undergraduate nurses: a practice development approach. Nurse Educ Pract. 2015;15(6):512-516.

9. Ozelie R, Janow J, Kreutz C, Mulry MK, Penkala A. Supervision of occupational therapy level II fieldwork students: impact on and predictors of clinician productivity. Am J Occup Ther. 2015;69(1):6901260010p1-7.

10. Frakes KA, Brownie S, Davies L, Thomas JB, Miller ME, Tyack Z. Capricornia Allied Health Partnership (CAHP): a case study of an innovative model of care addressing chronic disease through a regional student-assisted clinic. Aust Health Rev. 2014;38(5):483-486.

11. Thomas Y, Dickson D, Broadbridge J, et al. Benefits and challenges of supervising occupational therapy fieldwork students: supervisors' perspectives. Aust Occup Ther J. 2007;54(Suppl 1):S2-S12.

12. Aroian J. RN students: unobtrusive cost-effective change agents. Nurs Econ. 1992;11(5):308-311, 323.

13. Kavannagh J, Kearns A, McGarry T. The benefits and challenges of student-led clinics within an Irish context. J Pract Teach Learn. 2015; 13(2-3):58-72.

14. Mather CA, McKay A, Allen P. Clinical supervisors' perspectives on delivering work integrated learning: a survey study. Nurse Educ Today. 2015;35(4):625-631.

15. Rodger S, Webb G, Devitt L, Gilbert J, Wrightson P, McMeeken J. Clinical education and practice placements in the allied health professions: an international perspective. J Allied Health. 2008;37(1):53-62.

16. Spiers M, Harris M. Challenges to student transition in allied health undergraduate education in the Australian rural and remote context: a synthesis of barriers and enablers. Rural Remote Health. 2015; 15(2):3069.

17. Taylor MA, Brammer JD, Cameron M, Perrin CA. The sum of all parts: an Australian experience in improving clinical partnerships. Nurse Educ Today. 2015;35(2):297-303.

18. McMahon S, Cusack T, O’Donoghue G. Barriers and facilitators to providing undergraduate physiotherapy clinical education in the primary care setting: a three-round Delphi study. Physiotherapy. 2014;100(1):14-19.

19. Sahai K, Kotwal A. Anaemia prevention in the community: students as change agents. Med Educ. 2015;49(5):518-519.

20. Anderson J. Students - a force for change. Nurs N Z. 2014;20(1):31.

21. Klinger L, Bossers A. Contributing to operations of community agencies through integrated fieldwork experiences. Can J Occup Ther. 2009;76(3):171-179.

22. Duffy G, Ross SJ, Woolley TS, Sivamalai S, Whaleboat D, Miller A. Processes and outcomes for a successful engagement between a medical school and a remote Indigenous community in North Queensland, Australia. Rural Remote Health. 2013;13(2):2277.

23. Carney M. The development of a model to manage change: reflection on a critical incident in a focus group setting. An innovative approach. J Nurs Manag. 2000;8(5):265-272. 
Advances in Medical Education and Practice

Dovepress

\section{Publish your work in this journal}

Advances in Medical Education and Practice is an international, peerreviewed, open access journal that aims to present and publish research on Medical Education covering medical, dental, nursing and allied health care professional education. The journal covers undergraduate education, postgraduate training and continuing medical education

including emerging trends and innovative models linking education, research, and health care services. The manuscript management system is completely online and includes a very quick and fair peer-review system. Visit http://www.dovepress.com/testimonials.php to read real quotes from published authors.

Submit your manuscript here: http://www.dovepress.com/advances-in-medical-education-and-practice-journal 